\title{
ESTRATÉGIAS DE ENSINO PARA MEDIAÇÃO DO DESIGN NO PROCESSO DE APRENDIZAGEM NA TERCEIRA IDADE
}

Bruno Serviliano Santos Farias

Universidade Federal do Maranhão

brunoserviliano@gmail.com

Andréa Katiane Ferreira Costa

Universidade Federal do Maranhão

andrea.katianefc@gmail.com

Arthur Marques

Universidade Federal do Maranhão

arthurgarre@gmail.com
Ana Luiza Lima Rodrigues

Universidade Federal do Maranhão

analuizalimarodrigues@gmail.com

Raquel Gomes Noronha

Universidade Federal do Maranhão

raquelnoronha79@gmail.com

Márcio James Soares Guimarães

Universidade Federal do Maranhão

falecommg@gmail.com

Resumo: Este trabalho faz parte do Projeto de pesquisa "Mediação do design no processo de aprendizagem na terceira idade" desenvolvido pelo NIDA - Núcleo de Pesquisa em Imagens, Design e Antropologia, do curso de Design, da UFMA. Este segmento da pesquisa se ocupa em analisar as estratégias adotadas pela Universidade da Terceira Idade da UFMA. Para tal, foi empregada a pesquisa etnográfica com observações em aulas, entrevistas com docentes. A conclusão da pesquisa aponta para a importância do ambiente de ensino no processo de aprendizagem na terceira idade bem como os componentes afetivos contribuem para construir um ambiente seguro e estimulante para os discentes aprenderem, assim, pode-se pensar na contribuição do design no processo de aprendizagem.

Palavras-chave: Estratégia de Ensino. Processo de Aprendizagem. Terceira Idade

Abstract: This paper is part of research project "Design Mediation in the learning process in old age" developed by NIDA - Research Center for Images, Design and Anthropology, course design, UFMA. This segment of the research is concerned to analyze the strategies adopted by the University of the Third Age UFMA. For this, we used ethnographic research with observations in lessons, interviews with teachers. The conclusion of the research points to the importance of the learning environment in the learning process in the elderly and affective components contribute to building a safe and stimulating environment for students to learn, so you can think about the design of the contribution in the process of learning.

Keywords: Teaching Strategy. Learning Process. Seniors 


\section{INTRODUÇÃO}

Este trabalho faz parte do Projeto de pesquisa "Mediação do design no processo de aprendizagem na terceira idade" desenvolvido pelo NIDA - Núcleo de Pesquisa em Imagens, Design e Antropologia, do curso de Design, da UFMA - Universidade Federal do Maranhão. Este segmento da pesquisa se ocupa em analisar o ambiente de ensino da UNITI - Universidade Integrada da Terceira Idade da UFMA, partindo da pesquisa etnográfica com observações em salas de aulas e entrevistas com os docentes.

A UNITI é um espaço onde são desenvolvidas ações educativas baseadas na promoção dos idosos, considerando fatores de socialização, psicológicos, comportamentais e emocionais, que busca motivações e interesses para esse público. Nos últimos anos, o idoso vem sendo valorizado em diferentes áreas das ciências bem como em alguns segmentos da sociedade nos últimos anos. O processo de envelhecimento constitui uma preocupação mundial e várias pesquisas e políticas públicas estão sendo realizadas com o intuito de gerar qualidade de vida.

Entende-se a terceira idade como sendo uma faixa da população a partir dos 60 anos que está em crescimento, em torno de 3,5\% ao ano, segundo o IPEA. Comparando com as gerações de outras épocas percebe-se que a carga de trabalho é distinta das condições oferecidas às últimas duas gerações. Era comum, no passado, projetar uma velhice sombria, uma época para se pagar os pecados da juventude, a velhice era vista como um depósito de excessos juvenis, comentam Skinner e Vaughan (1984).

Era comum pensar na velhice quando se tinha contato com um idoso e o associava aos cuidados médicos ou à aposentadoria. No entanto, hoje, se relaciona a velhice com atividades que vão de educativas ao entretenimento e lazer. É uma fase que deve servir não apenas para se reconciliar com a velhice, conforme afirmam Skinner e Vaughan (1984, p. 28), mas também para recuperar parte da importância do idoso no convívio social.

Oportunamente, o país tem promovido várias ações no sentido de valorizar essa fase da vida. Em 2003, foi sancionado o Estatuto do Idoso com o objetivo de ampliar os direitos e a qualidade de vida dos cidadãos com idade acima de 60 anos, o que inclui ações efetivas tanto do Estado quanto da sociedade, que têm responsabilidades inalienáveis quanto à vida dos brasileiros que envelheceram (SHIRAIWA, 2008).

Os idosos podem apresentar dificuldades para manter a atenção, armazenar e processar rapidamente informações, formular conclusões, fazer interpretações, codificar e compreender determinados discursos. (SHIRAIWA, 2008). Esses declínios cognitivos podem ser acentuados por hábitos de vida como: ambiente de trabalho estressante, falta de condicionamento físico, depressão, estresse, uso indevido de medicamentos, entre outros. Tais declínios fisiológicos e cognitivos decorrentes da idade tendem a forjam uma imagem do idoso como cidadão não atuante.

Com maior perspectiva e qualidade de vida aliado ao amparo legal e ações afirmativas, milhares de pessoas idosas querem continuar suas atividades na sociedade, não ficar somente dentro de casa sem atuação alguma. Essas ações afirmativas promovidas pelo governo e instituições privadas têm o intuito de manter esse público conectado ativamente com o seu meio social. Um exemplo são os cursos universitários para a Terceira Idade. A educação pode reinserir o idoso nas atividades sociais, bem como ajudá-lo a recuperar sua subjetividade, e o exercício de diversos papéis: sociais, emocionais e psicológicos. Assim, ao olhar para a educação de pessoas 
na terceira idade percebe-se a necessidade de pensar em questões mais abrangentes como: condição física fragilizada pelo tempo, a estrutura familiar vulnerável e despreparada para lidar com essa situação e a privação material provocada pela situação financeira.

Ciente dessas questões, a UFMA desenvolve um Projeto de Extensão voltado para o ensino e a reinserção social de pessoas acima de 50 anos: a Universidade Integrada da Terceira Idade (UNITI). Desde 1995, através da parceria entre as Universidades Federal e Estadual do Maranhão, do Serviço Social do Comércio e da Secretaria de Planejamento, Orçamento e Gestão do Maranhão, foi criado o Projeto UNITI que representa, hoje, um espaço para ampla repercussão social, com o objetivo de oferecer à população da melhor idade a prática de atividades que fortaleçam a participação social e política; criar condições que garantam a esse público resgatar a autoconfiança e a autoestima e, assim assumir, conscientemente, o processo de envelhecimento e gozar o pleno exercício de sua cidadania.

$\mathrm{O}$ design pode contribuir com os processos de aprendizagem na terceira idade ao desenvolver artefatos didáticos adequados, mediar a relação ensino-aprendizagem, gerar um ambiente pedagógico mais seguro e eficiente. Tais intervenções envolve a investigação tanto das barreiras que obstaculizam a aprendizagem quanto dos fatores emocionais, pois permite analisar as experiências e o nível de participação dos alunos nas aulas, para que assim seja possível compreender os aspectos emocionais e o impacto que estes têm no ensino.

O presente estudo faz parte de um projeto maior que pesquisa as formas de mediação da educação na terceira idade, cuja primeira etapa foi realizada através de Pesquisa Etnográfica; com o objetivo de compreender as práticas de ensino no ambiente de aprendizagem, e entender a relação entre professores e alunos da terceira idade. A coleta de dados ocorreu através de técnicas de observação e entrevistas, e priorizou os ambientes e as formas de aprendizagem.

\section{CONTEXTO SOCIAL DA TERCEIRA IDADE}

Há uma carga depreciativa, carregada de preconceitos, estereótipos e estigmas em nossa sociedade que percebe os idosos como improdutivos, ociosos e disponíveis, o que os leva à exclusão e reforça o isolamento social. Em um país como o Brasil, marcado pela desigualdade econômica, precário acesso à saúde e à educação, diversidade cultural e influência climática contribui para delinear várias faces da velhice (CUBA, 2015). Como exemplo, cita-se a capital São Luís, que devido ao baixo nível nutricional, à dificuldade de acesso à saúde e ao clima equatorial, é comum as pessoas serem consideradas precocemente velhas, por terem uma aparência física debilitada, rostos marcados por rugas, pele enrijecida e ressecada.

O desprestígio da sociedade e a falta de uma cultura de valorização do idoso contribuem para que eles convivam em ambientes inadequados e desmotivadores. Tais deficiências reforçam a necessidade de políticas sociais para lidar com o processo de envelhecimento, não apenas com um fator demográfico. Desse modo, o fenômeno do envelhecimento envolve elementos heterogêneos, como gênero, religião, etnia, fisiologia, educação, economia, afetividade, cultura, etc.

A Teoria Psicossocial de Erikson (1976), na qual o estudioso lista os fatores que influenciam o ambiente de aprendizagem, evidencia-se a articulação entre os componentes cognitivos e sociais, com o propósito de converter situações negativas, tais 
como a vergonha, inferioridade, confusão e isolamento em situações positivas como a confiança, autonomia, iniciativa e identidade, visando melhorar a qualidade de vida por meio da reeducação. O ambiente não só influencia nessas questões como também promove adaptações que auxiliam na superação de desafios inerentes à idade. Para Erikson (1976), o fortalecimento das capacidades cognitivas através da educação e das relações sociais é importante para uma velhice bem sucedida. (Imagem 1).

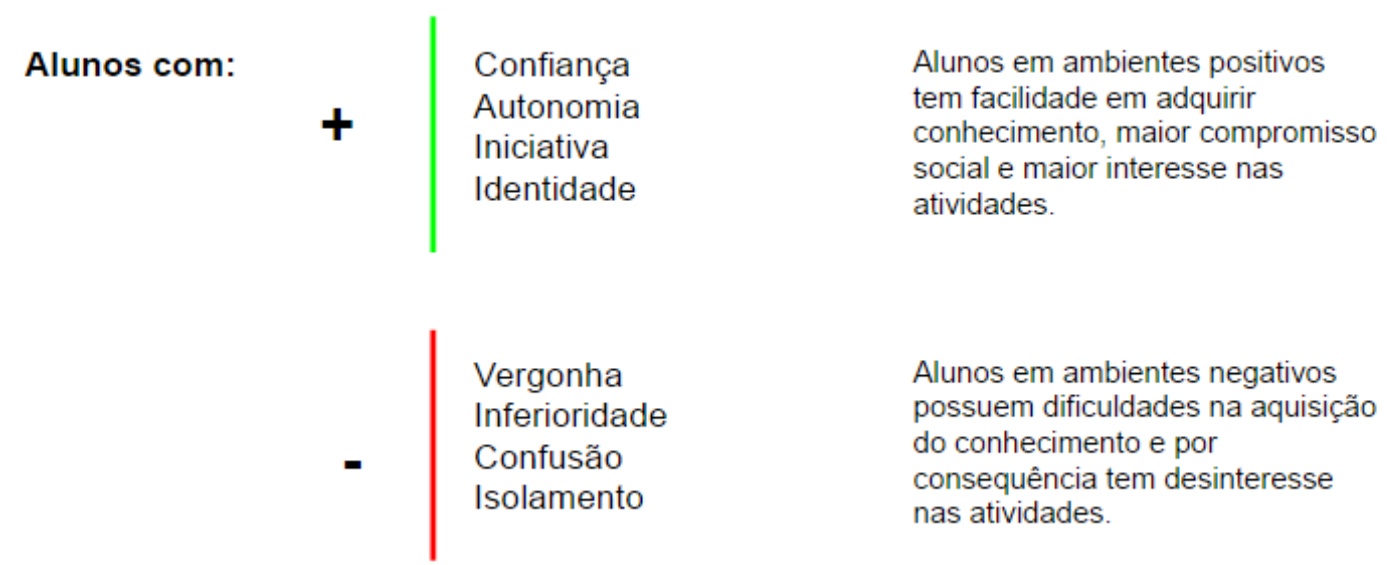

Imagem 1 - Aspectos emocionais no ambiente de ensino Fonte: resultado da pesquisa bibliográfica, São Luís, 2016.

\section{TIPOS DE ESTRATÉGIAS E FERRAMENTAS DE ENSINO NA TERCEIRA IDADE}

Antes de abordarmos os conceitos norteadores, foram definidos os temas essenciais para a compreensão e o desenvolvimento da pesquisa. Quando há referência aos tipos de estratégias reporta-se ao conceito de didática, que é definida como os meios, ferramentas e técnicas escolhidas ou disponibilizadas para mediar a relação ensino-aprendizagem (DALBOSCO, 2011, p. 24), desse modo se relaciona o caráter prático da educação, ao considerar ensino como transferência de informação.

Dalbosco (2011, p. 30) discute o conceito de educação e o apresenta como um "processo recíproco, espontâneo e assistemático de ensino-aprendizagem entre duas ou mais pessoas". Nesse aspecto, há destaque para a interação entre professor e alunos em um ambiente social, mas não exclusivamente no âmbito formal como o acadêmico. Assim, ao nos referirmos ao processo de educação envolvemos a interação entre professor e aluno com a intenção de transmitir informações através de certas técnicas e artefatos.

Importa ressaltar que não há uma técnica universal de ensino, como adverte Vianin (2013, p. 45). Ele alerta para o conceito de "acontonar" que se refere à estratégia de educação geral que resolve grande número de problemas, mas não convém para um desafio específico. Além disso, o autor ainda chama atenção para outro conceito, esse voltado não para o professor, mas para o aluno: "cabeça no guidom", no qual descreve a situação dos alunos que ficam imersos na realização do problema e têm dificuldades em olhar para a paisagem. Tais conceitos nos ajudam a refletir sobre a importância de utilizar estratégias de ensino adequadas para cada situação bem como permitir aos discentes que percebam as etapas da aprendizagem tendo uma visão geral de cada momento para que possam empregá-las em outras situações de aprendizagem. 
As etapas de aprendizagem citadas por Vianin (2013, p. 45) são: (1) planejamento do trabalho, (2) administração do tempo, (3) organização e sistematização das ações e, (4) adaptação da estratégia adotada. Ele ainda comenta alunos despendem mais tempo para compreender do que para executar. Nesse sentido, o professor deve se questionar:

- Se o aluno tem conhecimento base para entender o enunciado;

- Se a estratégia de ensino foi adequada;

- Se o aluno tem o controle dos processos empregados e;

- Se consegue responder no tempo adequado.

O uso de vários tipos de estratégias é positivo para os idosos, assevera Erikson (1976), uma vez que os desafios são constantes para esse público, como a busca por equilíbrio entre as limitações provenientes da velhice e a aquisição de informação. Mesmo com diversas perdas fisiológicas, sociais e financeiras, é possível buscar novas maneiras de manter ou mesmo melhorar o desempenho cognitivo e assim permanecer motivado.

A motivação dos alunos, apresentada por Vianin (2013), depende das representações que eles têm de suas competências, que integram os componentes afetivos, cognitivos e de aprendizagem. Dessa forma, os alunos podem atribuir seus desempenhos às causas externas ou internas. Estas podem ser modificáveis ou estáveis, controláveis ou incontroláveis, conforme ilustra o quadro1.

Quadro 1 - Relação desempenho-causa

\begin{tabular}{|l|l|l|l|l|}
\hline \multirow{2}{*}{} & \multicolumn{2}{|l|}{ Interna } & \multicolumn{2}{l|}{ Externa } \\
\cline { 2 - 5 } & Estável & Modificável & Estável & Modificável \\
\hline Controlável & $\begin{array}{l}\text { Estratégias de } \\
\text { aprendizagem }\end{array}$ & Esforço & Programa escolar & $\begin{array}{l}\text { Percepções do } \\
\text { professor }\end{array}$ \\
\hline Incontrolável & Aptidões intelectuais & Doença & $\begin{array}{l}\text { Nível de } \\
\text { dificuldade }\end{array}$ & Humor do professor \\
\hline
\end{tabular}

Fonte: Vianin (2013, p. 49)

A motivação é influenciada pela maneira como os discentes percebem as causas de um êxito ou sua dificuldade. Atribuir as dificuldades às causas controláveis ou estratégias inadequadas permite pensar em soluções para o problema, aumentando a motivação do aluno. Nesse sentido, adotar materiais didáticos permite vários tipos de estratégias de ensino. Bonsiepe (2011) afirma que esses artefatos devem sintetizar a informação, servir de apoio para o aluno ter mais segurança sobre o conhecimento adquirido e permitir maior autonomia. Nessa perspectiva, Skinner e Vaughan (1985) afirmam que ferramentas como listas, roteiros, repetição, anotação e mapas podem auxiliar a memória. Esses autores recomendam o uso de cartões para ajudar na organização e lembrança do pensamento devido ao fato dos idosos ficarem distraídos e confusos.

Quando um aluno não obtém êxito e manifesta atribuições de controle ele acaba por não imputar suas dificuldades a uma incompetência intrínseca, mas sim a uma má utilização das estratégias (VIANIN, 2013, p. 49). Ao contrário, os alunos que atribuem seus êxitos ou fracassos ao acaso, à oportunidade ou ao mau humor têm a tendência a 
se resignar. Esse fenômeno, também conhecido como "impotência adquirida", afeta alunos que sofrem fracassos constantes. Assim, argumenta Vianin, o melhor meio para desenvolver o sentimento de competência dos alunos é viver uma experiência positiva e compreender as causas do sucesso, seja por meio de estratégias adotadas, processos de controle entre outras razões. Atividades em grupo são valorizadas por gerar experiências de êxitos. Skinner e Vaughan (1985) explicam que tais atividades, acompanhadas de discussão, estimulam novas formas de pensamento uma vez que, segundo os autores, a falta de companhia é uma desvantagem especialmente para o idoso. Erikson comenta que compartilhar momentos com familiares e conhecidos gera um maior envolvimento social.

Tais questões envolvem atividades cognitivas que por sua vez contemplam a capacidade de compreender, memorizar e analisar, encerrando atividades mentais como exploração, identificação, comparação e indução. Através de estímulos sensoriais formamse as representações e mediante essas interage-se com o meio. Por isso, a inteligência é considerada a capacidade de utilizar processos cognitivos de forma eficiente.

A fadiga mental é uma preocupação constante para a terceira idade, pode ser mais nociva do que a fadiga física (SKINNER e VAUGHAN, 1985). Pode ser notada pelo uso de blasfêmias, por irritações constantes, por culpar os outros e não admitir erros, por protelar decisões, etc. Atividades de lazer e intervalos ajudam na recuperação mental. De qualquer forma é fundamental orientar o aluno nesses processos cognitivos de acordo com as categorias das informações, de suas relações e estratégias. Apontando nesse sentido Vianin (2013, p. 57) se preocupa em relacionar os tipos de conhecimento com as estratégias mais adequadas, que são:

- Declarativo - são informações objetivas como a capital do Maranhão, ou quem descobriu o Brasil. Estratégias mnemônicas são eficientes.

- Lexical - permite agrupar o conhecimento declarativo em conceitos-chave, assim o aluno pode organizar o mundo ou o conhecimento do mundo de forma que possa entender tanto os conceitos por comparação como também relacioná-los. Mapas mentais e esquemas são eficientes como estratégias.

- Procedural - habilidade de saber fazer, sequências de ações, se atualizar através de atividades concretas, assim é possível analisar como o aluno realiza uma tarefa. Desafios e exercícios são estratégias eficientes.

- Conhecimento Pragmático - responsável pela transferência do aprendizado, o importante é saber quando utilizar o conhecimento. Jogos e dinâmicas são eficientes para tal.

As questões supracitadas envolvem o arcabouço teórico da pesquisa sobre estratégias de ensino na UNITI/UFMA. Com base nessa revisão bibliográfica foi realizada uma pesquisa etnográfica com observações em sala de aula e entrevistas com os professores.

\section{MÉTODO DA PESQUISA}

As observações ocorreram durante três semanas de aula do mês de novembro, final do ano letivo quando a relação professor-aluno, as rotinas de ensino, assimilação do vocabulário da disciplina e familiaridade com as atividades desenvolvidas já estavam consolidadas. Depois, foram realizadas entrevistas semiestruturadas com professores selecionados, tendo como critério a disponibilidade. Buscou-se 
compreender as estratégias adotadas pelos docentes e os respectivos desempenhos dos discentes confrontados com aspectos os teóricos que norteiam a investigação.

Sabe-se que na contemporaneidade, a etnografia pode caracterizar-se mais por encontros do que por longas permanências, como afirma James Clifford (1997). O contato com os sujeitos da pesquisa - os informantes - pode dar-se a partir da vivência do cotidiano onde incide a pesquisa sem, no entanto, requerer uma longa permanência. As etapas descritas por Da Matta (1978) - a pesquisa de referências, a preparação para o campo e, finalmente, o estabelecimento da relação, a partir da empatia entre os atores envolvidos na pesquisa - requer tempo, mas também a disponibilidade emocional que se empenha em campo. Como resultado, dos registros da observação e da transcrição das entrevistas, foi possível elaborar uma "nuvem de palavras" com os termos mais recorrentes detectados nas observações e entrevistas (imagem 2).

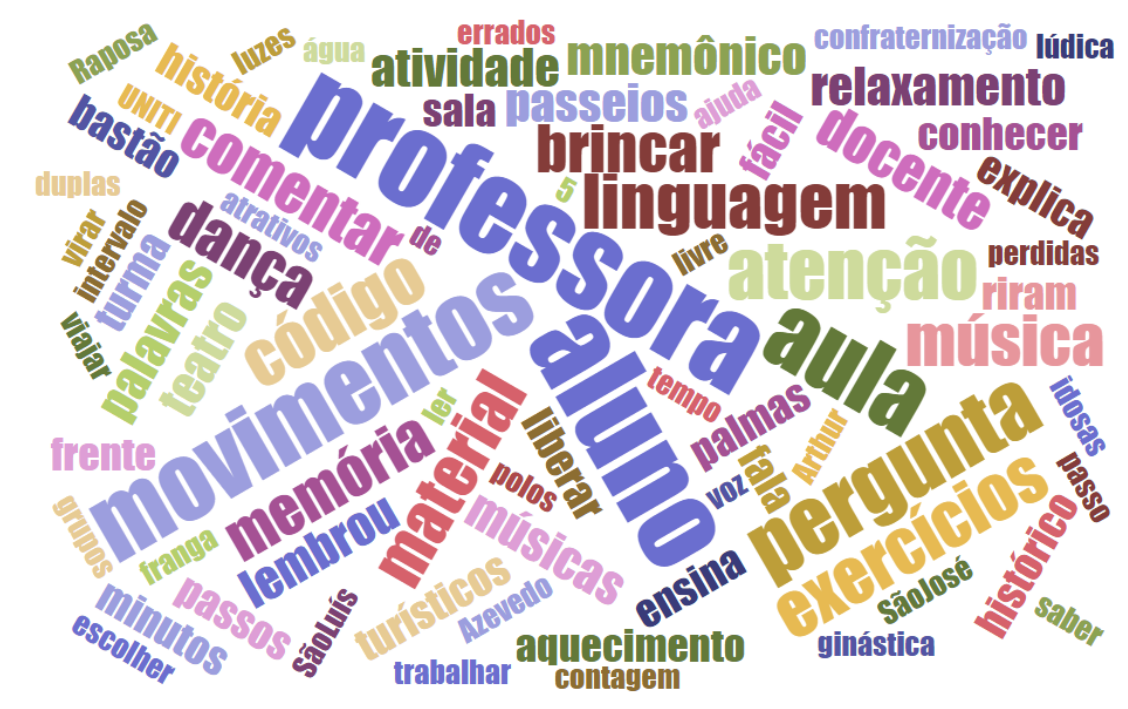

Imagem 2 - Nuvem de palavras

Fonte: resultado da pesquisa etnográfica, São Luís, 2016.

Mediada por essa nuvem de palavras percebemos que algumas questões se sobressaem mais do que outras. Questões relacionadas às ferramentas e estratégias de ensino como "movimento", "material", "linguagem", "música", "exercícios", "passeios" entre outras. Há também questões relacionadas ao ambiente de ensino e ao relacionamento entre professor e aluno como "brinca", "comentar", "riram", etc. Baseado nessas relações que se elaborou uma análise dos grupos.

\section{DISCUSSÕES DOS RESULTADOS}

O envolvimento social e emocional dos discentes com a Universidade da Terceira Idade da UFMA pode ser uma indicação do grau de motivação que eles têm com o projeto de ensino. Mesmo que tenham dificuldades, como foi constatado durante as entrevistas, muitas dessas barreiras são superadas em conjunto, compartilhando experiências e tornando-as positivas.

Vale ressaltar que as dificuldades são de várias ordens (desde física a cognitiva, fisiológica a social, afetiva a financeira) como constatadas pelas entrevistas e pela análise do perfil social dos alunos.

As didáticas dos professores do projeto da terceira idade na UFMA valorizam as relações sociais. A educação torna-se um incentivo para as relações interpessoais, seja 
com um simples elogio, com o consentimento dos relatos pessoais dos alunos durante as aulas, muitas vezes ocupando grande parte do horário, ou em eventos fora do ambiente de ensino. Elogios, seja por parte dos professores ou dos alunos, servem como forma de estímulo e reconhecimento do esforço que tiveram.

Esse clima amistoso permite o equilíbrio entre as limitações provenientes da velhice e a aquisição de informações na medida em que os componentes afetivos reforçam a aprendizagem. Assim, o desenvolvimento de outras atividades como expor um aluno perante a turma em um exercício no quadro, atividades organizadas fora do ambiente de ensino, visitas às cidades ou teatros, festas e encontros não se tornam barreiras no aprendizado, nem geram sentimentos negativos como vergonha ou inferioridade.

Desse modo, o processo dialético-interativo da UNITI define bem as estratégias educacionais do projeto da terceira idade da UFMA que centra seu método de ensino nos alunos e, como consequência, gera um ambiente no qual eles sentem-se confiantes, autônomos e torna possível explorar as identidades de cada um dos participantes.

Durante as aulas há o uso de diversas ferramentas como: Datashow, vídeos, sons. No herbário há uma horta na qual os alunos podem imergir nas disciplinas e ter contato direto com os aspectos ensinados em sala de aula, além de outros recursos como uso de ônibus, jornais, revistas e cartolina. Desse modo, essas ferramentas permitem vários tipos de atividades utilizando diversas estratégias de ensino como dinâmicas em grupo ou individual, turismo e visitas; acompanhamentos em casa e consulta do conteúdo fora do ambiente da sala de aula. Recursos visuais como o Datashow, jornais e revistas contribuem para ilustrar e enriquecer o aprendizado ou mesmo complementar uma experiência através de outras didáticas como visitas e viagens. Sobre isso uma professora comentou que utiliza recursos audiovisuais, como filmes e Datashow e depois mostra in loco. As visitas, segundo a professora estimulam as lembranças.

Percebeu-se, tanto nas aulas teóricas quanto nas entrevistas, dois fatos curiosos: o primeiro diz respeito à falta de imagens em alguns artefatos didáticos. Considerando a baixa escolaridade de uma parcela significativa dos discentes, a ausência de elementos pictóricos em artefatos didáticos pode dificultar a aprendizagem; o segundo refere-se à solicitação de vários professores para os alunos não anotarem durante a explicação alegando que pode privá-los da explicação, diminuindo a atenção. No entanto, muitos deles insistiam em anotar. O fato da insistência em anotar, contrariando os professores, pode estar relacionado à (in)segurança da compreensão.

Ao comentar sobre a ética dos signos, Barthes (2004) afirma que não temos relações neutras com os signos. Nós, segundo o autor, fazemos operações de deciframento. Quando essas operações são familiares nos sentimos seguros, do contrário, sem a familiaridade, os signos seriam vazios. Confrontando o fato com essa argumentação poderíamos levantar a hipótese de que em vários momentos das aulas, principalmente nas disciplinas teóricas, os alunos anotam a explicação como forma de se sentirem seguros. Anotar se torna uma operação de resgate do significado para que o sentido não se torne vazio. Skinner e Vaughan (1985) reforçam tal argumentação ao comentar sobre a operação de anotar que poder ser uma estratégia eficiente para a terceira idade, na medida em que reforça o processo de aprendizagem e pode se tornar material de consulta. Esse material pode ser revisto em outros momentos e com a vantagem de estar na linguagem do próprio aluno. 
Nesse sentido, há várias estratégias para dar segurança no processo de entendimento das aulas, uma seria anotar, outro seria uma linguagem acessível. Uma professora comentou que emprega a linguagem mais fácil uma vez que muitos alunos não sabem ler, há outros com baixo nível de leitura e até aqueles com doutorado. Por isso a linguagem precisa ser acessível a todos; a docente comentou que evita termos técnicos. Ela comentou que ainda assim alguns têm dificuldade, principalmente no início da disciplina, pois são disciplinas que eles não tiveram contato, não vivenciaram. No decorrer do processo de familiarização, eles passam a entender com maior facilidade. Uma outra professora comenta que:

Eu tento ficar livre, usar linguagem bem livre, bem pop. Alguns passos têm nomes específicos tipo vai e vem, dois em dois. E eu tento deixar mais fácil tipo vai na frente, vais atrás, dois passinhos para um lado e dois passinhos para o outro. E não uso o nome que se usa na nomenclatura.

Outra estratégia adotada pelos docentes do projeto da terceira idade da UFMA é a atividade em grupos. Uma professora comentou que é comum ter rejeição entre os idosos, tanto a heterorrejeição como a autorrejeição. Foi consenso nas entrevistas com os professores que tais atividades exploram e estimulam atividades sociais e que podem ser verificadas através da euforia dos discentes, seja pelo contato físico, pela competição ou mesmo pela interação que reforça os laços afetivos. Assim, tanto as aulas de danças e disciplinas teóricas fazem uso de dinâmicas em grupo, passeios e viagens podem ser estimulantes por permitir tais atividades, pois trabalham a convivência entre os alunos idosos.

Em alguns momentos foi observado o fenômeno "cabeça no guidom", principalmente quando os professores chamavam os alunos para o quadro para responderem uma atividade ou quando pediam para expor opinião sobre determinado fato. Levantamos a hipótese que o fato de se expor em público gera uma ansiedade embora tal exposição não se torna uma experiência negativa, mas uma oportunidade para os alunos compreenderem o enunciado dos desafios e refletirem sobre as estratégias para solucionar a questão, muitas das quais orientadas pelos docentes ou mesmo por outros alunos.

Por fim, foi possível compreender a importância da autonomia cognitiva e motora para os alunos da terceira idade e como a educação pode contribuir. Nas entrevistas com os professores foi percebido que não ter uma boa memória, bem como se sentir inseguro com seus movimentos, fragiliza a confiança e a autonomia do idoso. Por isso, disciplinas que envolvem dança e memória contribuem para fortalecer a musculatura, melhorando a inteligência espacial e reflexos e melhora a capacidade cognitiva e por consequência o bem-estar dos alunos. Além disso, estratégias mnemônicas, nas quais os alunos são orientados pelos professores a repetirem o que aprenderam, contribuem para assimilar o conhecimento. Por outro lado, exercícios de relaxamento evitam a fadiga mental. Tais atividades são comuns em disciplinas práticas como dança e yoga que os preparam para as outras atividades, diminuindo o possível estresse.

\section{CONCLUSÃO}

Considerando o presente estudo uma etapa de um projeto maior, pode-se compreender diversas questões que estão envolvidas com as estratégias de ensino, tipos de ferramentas e a relevância do ambiente de ensino para os alunos na terceira 
idade. Para se obter tal compreensão foi necessário um longo levantamento bibliográfico sobre o contexto social, aspectos cognitivos e emocionais.

Posteriormente foi realizada uma pesquisa etnográfica no qual foram observadas três semanas de aulas durante o mês de novembro e em seguida foram realizadas entrevistas com os professores. O objetivo foi compreender a relação entre professor e aluno, as estratégias de ensino adotadas e a influência de tais estratégias no ensino na terceira idade.

Foi possível perceber a importância do ambiente de ensino para os discentes da terceira idade que procura a UNITI por se sentirem sozinhos e encontram no projeto de ensino um espaço que permite resgatar suas identidades, compartilhando experiências, melhorando sua autoestima e confiança. Tais questões não invalidam as dificuldades fisiológicas ou econômicas, mas os componentes afetivos ajudam a equilibrar tais barreiras com aquisição das informações e laços sociais. Mesmo em situações que poderiam ser percebidas como embaraçosas, como ir ao quadro, é entendida como mais uma atividade de ensino.

A Universidade da Terceira Idade da UFMA disponibiliza várias ferramentas que permitem o desenvolvimento de diversas estratégias de ensino, o que é benéfico para o processo de aprendizagem da terceira idade, com dinâmicas em grupo, visitas guiadas e viagens que reforçam os laços sociais através da convivência. Tais atividades complementadas com recursos visuais e sonoros enriquecem a experiência, estimulando a memória. Entretanto, a falta de imagens de alguns artefatos didáticos e a impossibilidade dos alunos em anotarem algumas aulas, pode gerar insegurança no processo de aprendizagem.

De qualquer forma, todas essas estratégias de ensino em um ambiente favorável estimulam autonomia e confiança na terceira idade, permitindo o desenvolvimento e aplicações de estratégias de ensino. Compreender esse tema possibilita refletir sobre a relação entre as variáveis ambiental e social, bem como sobre de que forma o design pode contribuir para melhorar essas relações e as estratégias de ensino com suas ferramentas. Pretende-se com isso, em trabalhos futuros, estudar o ambiente de ensino e as ferramentas didáticas empregadas pela UNITI/UFMA e propor intervenções a fim de melhorar o desempenho dos alunos e do projeto.

\section{REFERÊNCIAS}

BARTHES, Roland. 0 grão da voz. São Paulo: Martins Fontes, 2004.

BONSIEPE, Gui. Design, Cultura e sociedade. São Paulo: Blucher, 2011.

DALBOSCO, Claudio A. Kant \& a educação. Belo Horizonte: Autêntica Editora, 2011.

CLIFFORD, James. Routes: travel and translation in the twentieth century. Cambridge: Harvard University Press, 1997.

CUBA, Conceição de Mara G. Braga. Guarnicê e cidadania na amizade dos idosos cariocas e ludovicenses. São Luis: Edufma, 2015.

DAMATTA, Roberto. O ofício do etnólogo, ou como ter -Anthropological Blues. In: NUNES, E. O. A aventura sociológica: objetividade, paixão, improviso e método na pesquisa social. Rio de Janeiro: Zahar Editores, 1978. p. 23-35.

ERIKSON, E. H. Identidade, Juventude e Crise. Rio de Janeiro: Zahar editores, 1976. 
SHIRAIWA, Juliana Couto Silva. 0 reconhecimento de pictogramas em interface gráfica digital pelo usuário idoso - o caso do Portal Pró-cidadão da PMF.

(Dissertação) Mestrado. Universidade Federal de Santa Catarina, 2008, Florianópolis. SKINNER, Burrhus Frederic; VAUGHAN, M. E. Viva bem a velhice: aprendendo a programar a sua vida. São Paulo: Summus, 1985.

VIANIN, Pierre. Estratégias de ajuda a alunos com dificuldades de aprendizagem. Porto Alegre: Penso, 2003. 